\title{
Moral Deliberation and Desire Development: Herman on Alienation*
}

\begin{abstract}
I
In chapter nine of The Practice of Moral Judgment (1996b) and her later article "Making Room for Character" (1996a), Barbara Herman offers a distinctive and interesting response to a set of concerns involving the idea that Kantian ethics objectionably alienates us from personal relationships and commitments. Broadly speaking, these concerns take one of two general forms: Some accounts emphasize the practical marginalization of personal interests and relationships, arguing that the Kantian's open-ended commitment to impartial overriding moral requirements threatens to leave the agent little or no practical room for the sorts of relationships and commitments that we think of as important in (or essential to) a recognizably human life. A related but more formal variant emphasizes the internal perspective of the agent and the structure rather than the scope of moral commitment. On this account, the problem is said to lie in the requirement that we are only to act on reasons justifiable from an impersonal universalizing point of view and the way in which this requirement precludes the kind of partial and personal reasons for action said to be essential to individual agency and a sense of self ${ }^{1}$.
\end{abstract}

Responding to concerns like these, Herman argues that we should think of practical deliberation and the way in which desires are formed and become interests differently: She proposes a deliberative field model of practical deliberation in which interests are normalized against the background of other concerns and a developmental model of desire formation in

\footnotetext{
* Author's pre-print version. Article published in Canadian Journal of Philosophy, Vol. 39:2 (2009). https://www.tandfonline.com/doi/pdf/10.1353/cjp.0.0049
} 
which desires evolve in the context of a deliberative field, becoming developed incentives and interests that directly internalize other norms. The result is a complex integrated value model ${ }^{2}$ meant to reconcile the moral and the personal in a distinctive way: one that assigns moral value to personal interests but also preserves a robust sense of partial and direct commitment to these interests in a way that is intended to be responsive to an imagined critic's demand for more than a mere permission to act from motives of connection ${ }^{3}$.

I argue here that while Herman's model offers us an attractive and plausible account of practical deliberation and desire formation, it cannot ultimately meet the critic's concerns. I claim that the deliberative field model does not change the basic structure of moral deliberation troubling to the critic and that the significant changes here are found specifically in organic elements in the account of desire formation and the integrated value model these elements imply. I then argue that thinking of desires as developing in the reason-responsive manner she envisages will not, itself, satisfy the critic either in the sense of offering us an affirmative moral endorsement of personal relationships or in the more limited sense of a structural accommodation of these interests. Instead, I argue that the Kantian must be able to defend these interests on specifically moral grounds, that they can and should do so on the basis of indirect arguments, and that these arguments need not be seen as objectionably alienating.

\section{II}

Herman initially discusses a cluster of issues associated with the charge of alienation in Chapter 2 of The Practice of Moral Judgment. Adopting what has become a fairly common strategy in response, she suggests here that we can think of moral commitment as ordinarily operating in the background in a way that allows appropriately personal commitments. As long 
as it is true that the motive of duty functions in the agent's willing in a limiting condition role constraining and informing her choices, the claim is that the agent can routinely defer to other motives and act directly from them and that in doing so her will is still good. So, for example, the duty of beneficence may require me to render assistance to people, including my friends, but I will also typically want to help friends and have reason to think that they would prefer being helped personally by me (in a way that directly acknowledges our mutual affection). In these circumstances it is suggested that there is no necessity that I act directly from moral duty; I can defer to these other reasons, acting in a manner consistent with duty but doing so directly from motives of connection, and, as long as I remain committed to duty in its limiting condition role, my will can still be regarded as good. Recognizing this limiting condition role of the motive of duty is thus said to allow us to claim that Kantian ethics can permit actions motivated directly by personal affections and commitments and that values like these can be regarded as compatible with a moral life ${ }^{4}$.

In chapter nine of The Practice of Moral Judgment, however, Herman revisits this issue and explicitly acknowledges that this kind of response will not satisfy critics of Kantian ethics:

... [P] ermitting action from motives of connection does not fully resolve the problem. Even though there is nothing wrong with acting from a motive of connection in circumstances of obligation, the Kantian is likely to insist that action so motivated has no moral worth. ... The critic of Kantian ethics objects to the fact that no moral value is assigned to maxims or motives of connection. Toleration is not enough (Herman, 1996b, 186, emphasis added).

The critic regards this kind of bare accommodation as inadequate because motives of connection are viewed merely as non-moral interests that happen, under the right conditions, to be compatible with moral life and argues that this model therefore does not properly reflect the nature and significance of these relationships. 
Herman considers and rejects two other responses available to the Kantian that are intended to go beyond mere toleration of these other interests and uses the perceived shortcomings of these alternatives to frame her own response. The first of these alternatives - the "mental health" argument - assigns moral value to personal relationships and important commitments on instrumental grounds, arguing that these relationships and interests have a vital role to play in ensuring the basic psychological integrity of human agents essential to their continuing moral agency. From the critic's perspective, this kind of response is too indirect. Personal relationships are now regarded as having affirmative moral value, but only contingently and derivatively insofar as they tend to ensure the integrity of moral agency. The critic thinks that the problem for the Kantian is not simply a matter of integrating motives of connection associated with the affective side of our nature into a moral life characterized in terms of respect for norms of rationality. Motives of connection must be acknowledged and valued on terms that properly reflect both the structure and the significance of these relationships. To the critic, any acceptable solution must preserve the basic partiality and immediacy regarded as constitutive of these commitments and not marginalize them or render them hostage to their serving some further moral purpose. Endorsing the critic's concerns, Herman suggests that this response will:

... not really satisfy those who find the issue in the need to justify the motives of connection in the first place. Nor should it. This way of arguing the value of connection or attachment depends on its role in supporting the "mental health" of the moral agent (Herman, 1996b, 187).

The second kind of reply that Herman considers but rejects thinks of personal relationships and commitments as having direct value in their own right, either as distinct sources of moral value or as goods with intrinsic non-moral value. Herman reminds us that the Kantian is committed to the priority of moral demands and cannot therefore endorse a distinct value model that distinguishes between moral value and the non-moral value of personal relationships and 
gives at least limited priority to the latter ${ }^{5}$. Nor, similarly, can the Kantian endorse a view that distinguishes between different types of moral value and suggests that sometimes the moral value of personal relationships will take precedence over the requirements of moral duty.

Contrasting her approach with these alternatives and committing herself to meeting the critic's challenge, Herman proposes a significantly different kind of response. She suggests that we should rethink our model of practical deliberation and the relationship between desires and affects and rational norms:

I want to accept that it is reasonable to expect a moral theory to give noninstrumental expression to the role that sociality and the partiality of connection play in human life. To show that and how Kantian ethics does this, we must restart the discussion taking instruction from the fact that the affective life is not in general independent of various norms of rationality. This creates space for the claim that connection itself could be partially dependent on or a function of moral value (Herman, 1996b, 189).

With this end in mind, she begins by contrasting the deliberative field model of practical deliberation that she proposes with the plural interest model she associates with the basic problem here. In the plural interest model, practical deliberation is essentially just a matter of reflecting on the relative priorities of different interests regarded as independent concerns, and deciding which of these has the greater "weight". Viewed in this way, moral and other interests and commitments are regarded as different forces pulling the agent in various directions with different weights. The problem then is that thinking of moral interests as always having priority assigns them an absolute weight such that whenever a moral concern is involved, the agent is always required to simply and immediately defer to it. When partial commitment and moral requirement happen to pull in the same direction, our personal interests may give us further reason to do something, but, when they conflict, the unconditional priority attaching to impartial moral requirements demands unequivocally that they hold sway. Viewed in this way, all our 
other interests and commitments are rendered utterly contingent and disposable; partial and personal commitments seem impossible, and the charge of alienation quickly follows.

Herman proposes that we substitute a different deliberative field model of practical reflection. In this model interests and commitments are understood as being part of a broader context - a deliberative field representing the agent's evolving overall conception of her good that incorporates her various concerns, interests, projects, etc., along with any regulative principles she thinks of as integrating, organizing, and prioritizing these ends and interests in the context of the life that she makes for herself. Within this field, particular interests and commitments are understood to be normalized to the agent's deliberative field in the sense that they come to internalize and directly reflect other concerns and general regulative principles. So, for example, an agent who attaches very great value to his relationship with his spouse but who also has an interest in career advancement may understand the latter in the context of the former and, when he does so, will think of it differently in light of this other value. Thus, while he desires a better or more fulfilling job, he comes to conceive of this desire as only warranting a limited range of options and would not seriously consider employment requiring extensive travel, overtime, etc., even though this may clearly be the best way of meeting his goal of career advancement.

A commitment to morality is then said to regulate the moral agent's deliberative field in much the same way, just on a larger scale. Functioning as an overarching regulative value, the commitment to respect for persons will be internalized in the agent's other interests, commitments, etc. and will be reflected in the way that these other interest are understood. So, while I place great value on my relationship with my spouse and act directly from motives of connection with her interests in mind, I nonetheless think of this interest as being normalized to 
my other concerns, including my overarching and regulative commitment to morality. And so, while I do not think twice about buying my spouse an anniversary present in normal circumstances and I do so directly because she is my spouse and I love her, I also understand that I cannot favor her at all times and in all contexts and do not think of my interest here as extending this far.

This deliberative field model informs and deepens the earlier suggestion that the motive of duty can function in deliberation as a background limiting condition but is not, taken in isolation, directly responsive to concerns with the demand for something more than mere toleration of motives of connection and other important personal interests. The idea of a deliberative field differs from a plural interest model primarily only in terms of degree or scope. Rather than thinking of agents as weighing interests against each other in isolated acts of particular deliberation, we think of them as engaged in a broader ongoing meta-project of mutual accommodation and integration in which they seek to systematize their various long and short terms projects and to adjust their priorities periodically as situations and interests change. Within the agent's deliberative field, moral deliberation would thus remain a matter of integrating overriding moral requirements into one's practical endeavors and would raise the same general concerns. We can imagine that agents will come to rationalize their other concerns in a way that they might be said to have internalized moral constraints. So, for example, having judged that certain interests are permissible and various means to realizing them are ordinarily acceptable, I do not then need to deliberate about acting in pursuit of these interests in normal circumstances. We need not be in the position of having to explicitly weigh interests moment by moment on the scales of moral permissibility, but, to the extent that integration into a deliberative field takes this more explicitly reflective form, motives of connection and other interests and commitments will 
again be understood as regulated by overarching moral requirements with deliberative priority. As such, the agent will still be in the position of someone forced, at least on reflection, to view all of their interest as potentially hostage to moral concerns in the sense troubling to the critic.

The key element in Herman's proposal does not therefore lie in the deliberative field model per se. The key change lies, instead, in the details of normalization and, in particular, in the organic model of desire development that Herman thinks is involved in this process. In Making Room for Character she suggests that we reject a simple "desire-belief" model of action in which already substantially formed desires for particular objects are thought of as primitive elements in deliberation competing for motivational supremacy with other discrete interests and desires. She argues that we should think of desires, instead, as the outcome of a "reason responsive" developmental process. What we think of as desires begin in "original orectic states" consisting in an agitated condition in an organism prompting it to a mechanical response. These orectic states become desires for particular types of objects through a developmental process reflecting the nature, history, and circumstances of agents and are shaped and focused by this process. So, for example, my desire for food begins in an original natural condition of agitation occasioned by an energy deficit that prompts a mechanical response. Over time this orectic impulse evolves into a formed desire oriented towards some set of particular objects and does so in the context of a range of other impulses, desires, interests, etc.

Evolving in this way, the desire itself is shaped by the process: The original impetus becomes a desire for specific types of things oriented, in part, by other interests the individual has in maintaining their overall health, experiencing gustatory pleasure, complying with religious commitments or norms of etiquette, and so on. In particular, Herman suggests that insofar as we are rational beings, our desires will tend under normal conditions to evolve in a way that is 
responsive to the principles of practical rationality basic to our nature and will therefore come to internalize moral norms, reflecting them directly in the way our desires are understood.

Importantly, Herman thinks of this developmental process as a natural and, at least in part, organic process in which desires and interests evolve in a manner responsive to practical principles without these necessarily being explicitly brought to bear in conscious reflection and deliberation. Distinguishing reason-responsive from reason-following development, she emphasizes the "enmeshed" codevelopment of desires and rational capacities in human development (Herman, 1996a, 46). Like our desires, our rational capacities develop over time and Herman argues that nascent rational capacities will be "expressed in prerational structures of perception, recognition and the like" $(1996 \mathrm{a}, 42)$ and that these will normally influence the development of desires.

On Herman's view, then, desires are the result of a complex evolutionary process in which naturally given orectic states evolve into formed desires for particular objects under the influence of a wide variety of factors, including the rational principles constitutive of our basic nature. Combining the developmental account of desire formation with the deliberative field model of practical deliberation she argues that we should think of deliberation differently:

The fact that desires have a history (and a natural history), combined with the fact that human development is reason-responsive, alters the way we should think about deliberation and judgment. In the mature agent, objects of judgment (puzzles about what to do, questions about what is right) will present themselves already laden with deliberative and evaluative content (Herman, 1996a, 46).

Viewed in this way, the normalization of desires and interests within an agent's deliberative field is not then a matter of subjecting independently formed and understood desires and interests to distinct regulatory moral principles and admitting them to the court of deliberation on the 
condition that they pass moral muster. Interests and desires take their place in the deliberative field already informed by the moral and other considerations that have shaped their development:

An incentive is present in the deliberative field in what we might call a normalized or rationalized form - as a possible motive - to the extent that its representation and affective significance have been transformed from that of an impulse or an intentional disposition into a rational value (Herman, 1996a, 49).

To the extent that our interests and desires have come to directly embody rational principles in this way, we will normally have no reason for further moral deliberation in acting in their pursuit. If, however, we find ourselves in an unusual situation where the moral course is not immediately clear, we are not now in the position of someone forced to bring to bear external constraints and to sacrifice one interest for another. Thinking of our interests as already embodying principled moral commitments, these situations will merely be occasions for further reflection on their form and scope.

Herman emphasizes that this kind of normalization will be a complex and ongoing process: desires will differ in the extent to which they have evolved in a reason responsive manner and changing interests, improved understanding, and new circumstances will all necessitate ongoing reflection and revision both in moral terms and in terms of our other concerns. It is, however, the organic and reason-responsive process of desire evolution that changes the basic structure of deliberation here. Thinking of the development of desires and interests as organic and reasonresponsive allows us to think of desires and interests as being meaningfully partial but also as given in deliberation in a form naturally responsive to further moral reflection and refinement. To the extent that our interests and desires are at least partly shaped by reason (or by emerging pre-rational structures of consciousness), and this process is understood to take place below the 
level of conscious deliberation, our personal interests and desire are given in deliberation already understood in moralistic terms and we therefore do not have to reason about them from an independent moral point of view. So, for example, I do not think of myself as having an interest in the well-being of my children that I am subsequently required to modify or externally govern on the basis of moral considerations. Instead, I have a naturally moralistic interest in the welfare of my children amenable to further refinement and reflection on its own terms (including the moral terms partly constitutive of the interest). I am not then in the position of someone whose deepest interests are supposed to be permanently subject to external constraint and regulation and the opposition of interests basic to the problem of alienation has disappeared.

This evolutionary model of desire formation thus changes the way that self-interest is understood. The mature moral agent is not someone pursuing an independent conception of their own self-interest who is willing for some further reason to regulate the pursuit of their other nonmoral interests under the auspices of moral rules. They conceive of their interests differently, regarding the objects of interests and desires as things they value in their own right, but understanding their value as implicitly reflecting the range of their other concerns, including their moral concerns. More generally, they do not think of themselves as torn between what they want to do and what they ought to do:

The fully rational motive of self-interest does not carry a presumption of independent authority in the agent's deliberative field. It is not that the moral agent ignores her interests or her advantage. Rather, her conception of self-interest has developed, been shaped or altered, in a reason responsive way (Herman, 1996a, 53).

\section{III}

This is a subtle and interesting response, but it is not ultimately responsive to the problem vexing the critic. To see this it is helpful to begin by recalling the two ways in which the problem 
of alienation, and thus the critic's demand for something more than toleration of motives of connection can be understood. Reflecting the practical variant of concerns with alienation, this demand is naturally interpreted positively as a demand for an affirmative endorsement of the relationships involved, one that reflects the pervasive concern that impartial Kantian morality cannot take these motives sufficiently seriously and afford them an appropriate place in moral life. This affirmative reading of the critic's demand is reflected in Herman's characterization of their concern when she suggests that, "The critic of Kantian ethics objects to the fact that no moral value is assigned to motives of connection" $(1996 \mathrm{~b}, 186)$. It is also suggested both by the specific emphasis on very deep personal relationships like those between spouses and between parents and children, and by the way in which she characterizes this kind of "intimacy and connection" as being "necessary" to the "form of life we call human" $(1996 b, 186)$.

Without further detail, Herman's solution clearly does not meet the demand for this kind of affirmative endorsement. Her argument is a formal and general one meant to suggest that a reason responsive developmental process will result in evolved desires and interests that internalize universal moral requirements. Ideally at least (given good developmental circumstances), this process is presumably meant to rule out some interests and it is certainly intended to routinely influence the way interests come to be understood. She does not, however, argue that this process will result specifically in reason responsive motives of connection (at least under good developmental conditions) or that these interests will take something like an appropriate form. Specific questions of inclusion and scope are left open and represent substantive issues presumably to be decided by consideration of the details of the moral theory embedded in the reason responsive process. Thus, whether, even under good developmental conditions, my natural impulse to further the well-being of my son will survive this reason 
responsive developmental process and what form this interest will reasonably take are matters that will depend on the precise form of the rational principles involved in this process. ${ }^{6}$

Absent more discussion of the particulars of the developmental process and the moral principles at work in it, then, there is no affirmative endorsement of motives of connection in particular or of any specific personal interests here. Herman's characterization of her own proposal and the details of her solution seem, however, to reflect a more limited understanding of the requirement that a moral theory do more than merely tolerate motives of connection. The explicit goal she sets herself is to show that Kantian moral theory is capable of giving "noninstrumental expression to the role that sociality and the partiality of connection play in human life" $(1996 b, 188)$ and she is careful to emphasize that her central claim is one about the "structure of deliberative commitments" and not their practical scope (1996b, 200). Thinking of desires and interests as developing organically in the reason-responsive manner she envisages, her central claim seems to be that Kantian ethics can be said to go beyond merely tolerating motives of connection in the more limited sense that it allows us to see the actions of agents as flowing directly from personal commitments in the sense discussed above.

I take it, therefore, that Herman's response is primarily directed at the narrower and specifically formal version of the alienation problem alluded to earlier. Reflecting this concern, Bernard Williams claims that utilitarianism is incompatible with personal integrity in the sense that a commitment to the impartial maximization of utility precludes any possibility of a personal point of view (Williams, 1981). He concedes that Kantian ethics is not committed to maximizing good and does not therefore have exactly the same problem, but the commitment of the Kantian to impartial and universal moral norms is said to give rise to an analogous difficulty. The Kantian agent is not in the position of the utilitarian forced to give equal weight to the interests 
and reasons of others and to then act impartially to promote overall good, but she is required to act only on principles that are universalizable and therefore only on reasons that could be anyone's, and is only permitted to act on reasons of her own to the extent that they have this universal impersonal form.

Viewed in this way, Herman's goal is a more modest one. The benefit of her account is meant to lie in the fact that it allows us to think of the committed moral agent as able to act directly on the basis of reasons that are relevantly her own, with practical questions about the scope of these interests then being regarded as raising substantive issues of moral theory to be addressed later at this level of discourse. If successful, this limited account still represents a key element in a potentially robust response to concerns with alienation in Kantian ethics. As we have seen, it allows us to think of these interests as personal commitments that also already internalize moral commitment. As Herman emphasizes, this does not obviate the need for moral theory - life may present us with difficult moral choices and new understanding, or novel circumstances, may occasion further moral deliberation. When this happens, however, we are not now in the alienating position of someone forced to justify distinct but nonetheless very deep personal interests from an independent moral point of view. As we have seen, deliberation now simply asks the agent to think more deeply about moral commitments already partly constitutive of her general concerns and interests. And, assuming we have an account of Kantian ethics that meets the practical concerns alluded to above, the claim then will be that moral life and personal interests can be regarded as appropriately reconciled.

Even this more modest claim cannot, however, be sustained without a substantive account of the moral theory at work in the developmental process. Herman's argument suggests that direct personal commitments and moral reasons can be formally compatible in the sense described 
above but it is conceivable that the moral theory embedded in the reason-responsive developmental process could effectively rule out any meaningfully self-regarding action. Thus, critics like Susan Wolf argue that the open ended nature of the commitments required by imperfect duties is such that they must have the effect of eliminating any opportunities for selfregarding action (Wolf, 1982). Thinking of the development process as being responsive to reasons like this, then, it is conceivable that any desires that survive this process will have to be understood as contingent and hostage to the needs of others in a way that will render them practically empty. Recognizably personal interests and meaningful motives of connection may then result from a reason-responsive development process and they may be assigned affirmative moral value consistent with their nature and with the importance we afford them. Whether this is the case or not, however, will depend essentially on the details of the moral theory in question, and, given that it was precisely this kind of mediating role assigned to moral theory that troubled the critic to begin with, they are unlikely to be comforted by this proposal without careful discussion of these details.

From the point of view of both practical and more formal concerns, then, the critic's concerns cannot be addressed without first directly discussing the moral reasons at work in this reason-responsive process and the nature and scope of moral requirements in general. The critic wants reason to be confident that personal commitments will be possible in moral life. This requires both that the structure of moral reasoning will permit meaningfully partial commitments and that the extent of moral obligation leave practical room to make these relationships and interests real. Herman's focus is on the first of these issues and her solution is to restructure the way that desires and moral deliberation are understood in an effort to show that there need be no structural opposition between them. This cannot, however, be accomplished merely by re- 
describing the structure of our interests. We can think of our interest as being naturally moralized in this way but the exact form that this process takes is crucial. The critic will reasonably demand to be shown that reason-responsive development will preserve some meaningfully personal interests of the right sort. The problem this demand poses is not changed by thinking of my deeply partial love for my son as a moralized personal interest; even setting aside the question of scope, we need some argument to the effect that interests like these are permissible in moral life, and, hopefully, affirmatively valued from the moral point of view, and meeting these demands must involve discussion of the moral warrant for these interests.

Moreover, the same demand for moral vindication of the developmental model will arise immediately in the context of Kantian ethics. For the Kantian, the emphasis on reason-responsive development nicely captures the idea that moral interest is not something external and alien to be imposed from "without" on the agent's other interests. The elements of conscious deliberation in Herman's model are, however, also necessary to preserve the sense of reflective engagement and choice basic to Kantian moral life as this is usually understood. The virtuous Kantian is not someone following organically evolved patterns of behavior who acts morally merely from habit or design. She is someone who chooses rational self-government and is able to reflect on her life and choices and endorse these from the moral point of view, and she must therefore be in a position to reflectively endorse her inherited organic desires and interests. Moreover, Herman is clear that the outcome of the developmental process she envisages is not fixed. Given our common nature and shared rationality, we can expect similarities in the way interests evolve, but she emphasizes that this process will be influenced by a wide variety of external circumstances and that interests will continue to evolve in the light of further deliberate reflection and evaluation. The Kantian moral agent cannot therefore take evolved desires at face value and 
must, instead, have some understanding of these desires in their broader moral context both in order to think of them as permissible interests they are ordinarily free to pursue and to deliberate further about their legitimate scope as circumstances and interests change ${ }^{7}$.

Even at the level of the structural argument that Herman focuses on, then, the demand for further detail here is unavoidable from both the critic's and the Kantian's perspective. Given the priority of moral requirements and the need for reflective endorsement of our lives and choices, this detail must, it seems, be derived precisely from the kind of indirect argument that Herman begins by distancing herself from. Whether we think of motives of connection in terms of narrow self-interest to be governed by moral commitment or as moralized interests in the manner Herman proposes, the question confronting us is the same - what is the appropriate moral form of these relationships and what are their moral limits. To answer these questions, and thus the critics concerns, the Kantian needs an account of the principled moral basis of these relationships and thus some relevantly indirect account identifying their specifically moral significance and the appropriate weight to be given to them in the realm of moral reasons. Thinking of my love for my son as naturally already "moralized" does not change this fact, and, to the extent that we think of this process as an organic and unconscious one seems only to risk obscuring the basic issue.

\section{IV}

It seems to me, then, that we cannot avoid the need for indirect arguments intended to warrant the place of partial and personal interests in moral life and I want to end by reconsidering them. In particular, I argue here that taken in conjunction with aspects of Herman's account these indirect arguments need not be regarded as troubling in the way that she suggests 
and are not vulnerable to the kind of instability seen in their counterparts in consequentialist ethics.

There are two general forms that these indirect arguments take, both of which are also sometimes offered by utilitarians confronting the same concerns with alienation. The first kind of argument emphasizes the effective discharge of duties of aid and draws on the assumption that we know some people better than others and are therefore in a better position to help them. So, for example, I have a general imperfect obligation to help people and, if I am sincere in this obligation, I should presumably try to make sure that my efforts bear fruit. Given that I know my son better than I know strangers, I will have reason to prefer him, at least within some limits. On this argument, acting on my natural preference for my son is warranted from the moral point of view indirectly on the basis that it is likely to represent a more effective expression of my duty to help people in general. Broadening this argument, we might then claim that various personal relationships with people inform and facilitate a needed social culture of effective beneficence allowing us, again within limits, to show some preference for people in our wider communities on similar grounds. So, for example, just as I know my son better and am in a better position to help him, the same is true of my friends and neighbors and others in my immediate communities. The second kind of argument - the mental health argument - also attributes moral value to personal relationships and other interests indirectly on the basis of their serving some important moral interest. The standard form that Herman alludes to appeals to some psychological assumptions and argues that room for meaningful personal relationships and partial interests is essential to the psychological health of agents and, ultimately, to their capacity for moral choice and action. 
It is perhaps worthwhile noting that Kant makes arguments like these. He emphasizes, for example, the important supporting role that gratitude plays in facilitating an effective social culture of beneficence (Kant, 1991, 6:455-456). He also stresses the important role that trusted friends play in good judgment, suggesting that the "health of our understanding" depends on frank discourse with others (Kant, 1974, 7:219), and that since we cannot risk fully disclosing our thoughts to strangers who may exploit our candor for personal advantage, we must rely on trusted friends in order to properly inform our understanding of things (Kant, 1991, 6:472). More generally, he frequently emphasizes psychological considerations that he connects with our capacity for moral agency. For example, in the Doctrine of Virtue, he stresses the harmful psychological and social effects of ridiculing or defaming others, arguing that actions like these tend to undermine the individual's sense of their own worth and society's proper sense of the value of individuals, making moral choice and action more difficult (Kant, 1991, 6:466). Elsewhere, he emphasizes the importance of our own happiness suggesting, "Adversity, pain and want are great temptations to violate one's duty" and that "To seek prosperity for its own sake is not directly a duty, but indirectly it can well be a duty, that of warding off poverty insofar as this is a great temptation to vice". In this case, the agent's end is described as the "preservation of [her] moral integrity" and happiness is regarded as a "permitted means" for "removing obstacles to [the agent's] morality" (Kant, 1991, 6:388). Though not directly related to concerns with motives of connection, these and other similar remarks suggest that there is room for the kind of indirect argument under discussion ${ }^{8}$.

Reflecting the practical and formal variants of the alienation problem, I take it that there are two general concerns with arguments like these: The first has to do with the practical implications of these indirect arguments and whether they can motivate sufficiently robust room 
for important personal relationships and other interests in a moral life. In contrast, the second focuses on the form of these arguments, emphasizing their indirect nature and the alienating stance they seem to require of the agent. The issues raised by concerns with the scope of these arguments require detailed discussion of the casuistry of a moral view and are too broad to deal with in a paper like this. I am therefore going to confine my remarks mostly to discussion of the second formal concern, and return only briefly and in passing to the question of scope below.

As Herman suggests, far from resolving concerns about alienation, the form of these indirect arguments has seemed only to exemplify exactly the problems the critic is worried about. For example, I help my son with his homework and, when asked by my wife why I am doing so, I happily respond that I think I have a general obligation to help people and that, as luck would have it, I happen to be in a better position to help him, so I am morally permitted to do so. Or, in the case of the second form of argument, I help my son but this time respond to my wife's question by saying that helping him is vital to the preservation of my psychological, and hence my moral, functioning or integrity. These obviously inappropriate and alienating stances toward my son are not, however, entailed by the indirect form of these arguments. These characterizations of my actions assume that in order for them to count as moral actions, these indirect considerations must figure explicitly as my reasons for acting. Thus, it is because we imagine me replying to my wife's questions and explaining my own reasoning in these ways that we find these cases so troubling. As we saw earlier, however, Herman and other contemporary Kantians reject the idea that we must we always act in the moment from a sense of moral obligation or duty in order for our actions to have moral worth. They argue that we can think of the motive of duty as functioning in a limiting condition role, informing and limiting the way other interests are understood and taken up into action, without having to regard it as figuring 
explicitly in the agent's motive for acting at a given time. Thus understood, while I would offer a justification like this for actions of this type if one was required, I need not think of myself as acting directly on this basis in the moment of action. Instead, I will routinely act directly on the basis of my love for my son with the general understanding that morality constrains the permissible scope of actions like this and a commitment to abide by these constraints.

It is true here that my partial commitment to my son remains regulated by an overarching and authoritative commitment to doing what morality requires of me and that in some cases the costs to him of this commitment could conceivably be high. Perhaps, then, the problem is not that I must act in the moment from these kinds of indirect moral reasons but that this is how these relationships are ultimately understood by me and how, as a moral agent, I am required to value them. Setting aside the question of scope, however, the mere fact that my relationship with my son is governed by regulatory constraints need not detract from its immediacy or reduce his value for me to a merely instrumental one. The fact that something is valued on indirect grounds does not seem to simply entail that it cannot also have value in its own right ${ }^{9}$. Indeed, it is surely commonplace for us to think of our various interests as ordered and prioritized, and it does not follow from the fact that some are answerable to others that the value of regulated interests is thereby necessarily only instrumental. I can, for example, surely value my friends and my friendships for their own sake at the same time that I value them on other grounds and think of them as answerable to broader commitments I may have ${ }^{10}$. Similarly, I can surely value a great piece of art or a beautiful natural landscape for their own sakes at the same time as I think that preserving them is not worth the sacrifice of human life.

In this respect, it seems to me that the strength of Herman's account lies in the way it emphasizes the organic and natural development of different values in our lives and their 
subsequent evolution into complex interests responsive to a range of other concerns that we have. We do not arrive at these other values, as it were, ex nihlo - we do not begin with a clean slate and decide to value our children or to make acquaintances into friends in order to ensure our moral integrity or better discharge our duties, or, for that matter, on some other instrumental grounds (to realize our happiness, please God, etc.). As Herman emphasizes, the value of these significant others in our lives is a given, emerging from complex processes of nature and circumstances, and these interests evolve and change with the choices we go on to make: We have children, and then we find ourselves deeply invested in them in ways we never would have anticipated; we live among others and we come to value some specially as our friends; and, if we are lucky, sometimes we fall in love. In all of these ways and in many others we invest ourselves profoundly in other people and other interests that we value in different ways. From both the prudential and moral perspectives we may make good and bad decisions about these relationships and interests, but in both cases we deliberate against the background of concerns like these that are already to some extent given, in different degrees and in different ways, by nature and circumstances.

What regulatory moral principles then ask of us is that these other values be regarded as answerable to overarching and authoritative moral requirements. Viewing my other interests in this way may require me to abandon interests and will routinely limit their scope, but it does not simply entail the kind of troublingly alienating stance toward them envisaged by the critic. It does not require that I view my personal relationships only, or even predominately, through the impartial lens of moral detachment or that I rush out and have children in order to become a better moral agent. The mental health argument that Herman refers to is premised on the assumption of the very deep and personal value of these relationships for people in general and 
claims that their value is such that the psychological integrity of agents hinges on their being able to realize and promote values like this. Rather than objectionably instrumentalizing these concerns by reducing their value merely to the value they have from the moral point of view, this argument thus starts from the fact of deep personal affections and their significance in specific individual lives and claims that we have moral reasons to recognize and accommodate these values as they figure in peoples' lives ${ }^{11}$.

Viewed in this way these indirect arguments are therefore focused on preserving the experienced subjective value of deep partial connections in peoples' lives. It is true both that the arguments made on behalf of these personal connections are premised on the claim that these kinds of relationships ordinarily play a crucial role in our well-being and that in moments of abstract moral reflection the agent is required to understand this and be willing to consider their value from this more impersonal point of view. However, there is no reason to regard this as demanding an alienated stance on one's deep personal affections. I can think of personal relationships formed in the ordinary conduct of my life as having direct non-moral value for me at the same time as I understand their place in the broader context of my moral life in terms of this direct and deeply partial value and its central role in the psychological integrity of normal human beings. In ordinary contexts, when asked by my spouse or children why I do things for them, I am not required to adopt the lofty and impartial perspective of morality - I can answer directly, and in perfectly good faith, that I do these things because I love them. At the same time, however, I understand that love has its limits, and, when asked in another context to defend my partiality as morally permissible, I can do so. Thus, when asked by my son to justify my preference for him over strangers, I can explain that relationships like ours are part of the deepest fabric of a human life and serve to define us and to connect us with our lives and with others. 
Responding in this way, I appeal to the objective moral value of relationships like this and argue that, within limits, people are entitled to show special preferences for significant others and that my deep and personal affection for him falls under the auspices of this kind of moral consideration. Far from devaluing my personal attachment, the fact that I can also justify my personal commitment to him from my moral point of view seems only to add to its significance and value.

It seems to me, then, that once we distance ourselves from the idea that we must always act explicitly and only from a sense of the moral value of things and instead think of the motive of duty as ordinarily playing the kind of regulative role in desire adoption and formation that Herman envisages, the indirect form of these arguments should not be regarded as necessarily troubling. Notice also that in the context of Kantian ethics, these arguments need not be understood as vulnerable to criticisms that can be leveled against their consequentialist counterparts. Take, for example, the sophisticated consequentialism envisaged by Peter Railton. Railton associates the problem of alienation in consequentialism with the "subjective consequentialist's" commitment to explicitly consequentialist reasoning in choosing how to act and the way that this requires her to always weigh the value of personal commitments from the vantage point of impersonal utility maximization ${ }^{12}$. Railton argues that once we recognize that it is this explicit commitment to ongoing consequentialist reasoning that is the problem and that this commitment makes personal relationships vital to our psychological integrity impossible, we have good utilitarian reasons to forgo subjective consequentialism and to adopt a sophisticated variant instead.

Sophisticated consequentialism takes as its goal the realization of the most objectively consequentialist lives available to agents - the lives in which they are likely to contribute 
optimally to the production of utility overall. Railton argues that it is reasonable to think that human beings will produce more utility in the long run when they have room in their lives for special relationships and that these relationships cannot be realized without allowing directly partial actions. Recognizing this, he claims that the sophisticated consequentialist has reason to forgo subjective consquentialist reasoning and to endorse particular actions that do not maximize utility in the short run (on the grounds that doing so is necessary to ensure the most objectively consequentialist life available to the agent). Thus, citing the case of Juan, a married man working away from his family who decides to go home for an additional weekend rather then donating his extra cash to Oxfam, Railton suggests that:

It may be that Juan should have (should develop, encourage, and so on) a character such that he sometimes knowingly and deliberately acts contrary to his objective consequentialist duty. Any other character, of those actually available to him, would lead him to depart still further from an objectively consequentialist life" (Railton, 1988, p. 121).

The claim here, then, is that Juan's directly partial and suboptimal action can be justified from the sophisticated consquentialist perspective on the grounds that such actions are necessary to sustain the character that leads to the most objectively consquentialist life available to Juan. This solution is open to two different interpretations, each of which has problems. Railton emphasizes that the sophisticated consequentialist is not committed to requiring any particular model of moral reasoning and explicitly acknowledges the potentially self-effacing character of this view. Thus understood, it is possible that Juan's life may be being assessed and endorsed from a moral point of view he presently does not, and may never, affirm. Instead, his actions may be endorsed here on the grounds that they happen, unknown to Juan, to be those that contribute to the most utilitarian character and life available to him (given facts about his circumstances and psychology). Though not alienated from his personal commitments, it is hard to see this solution as reconciling the moral and the personal in a way that is responsive to the 
critics concerns ${ }^{13}$. Alternatively, we can think of Juan as a conscious sophisticated consequentialist committed explicitly to the goal of leading the most objectively consequentialist life he can. Thus understood, however, he is still committed to maximizing his contribution to utility overall and ought, therefore, to consciously strive to reduce his tendencies towards suboptimal actions. Thus, while he might think of himself as entitled to take that extra weekend home for now, he should see that his character is not fixed and ought, therefore, to try to reduce his dependence on these other interest over time, suggesting that the concern with alienation will only recur over time given a conscious commitment to sophisticated consequentialism and this kind of ongoing meta-reflection on his moral life.

The Kantian version of these indirect arguments can avoid these problems. The Kantian agent is committed explicitly to reflective rational endorsement of her choices and of her life in general, and acts morally only when they are consciously understood on moral terms. In reasoning in this way she is committed to conforming her choices and actions to principles of duty and not to the overarching goal of maximizing good and is therefore not subject to the same pervasive and relentless requirement to alter her character to optimize her capacity to produce good in the world. Much, of course, now hinges on a satisfactory resolution of the question of scope. We can argue that attributing moral value indirectly to personal relationships on the basis of their direct and important personal value allows us to give weight to these commitments in moral deliberation, but it is an open and substantive question whether these arguments can afford us sufficient and appropriate room for robust personal interests and affections.

In this respect, the mental health argument seems the more promising of these indirect arguments. It is surely plausible to claim that our psychological health is profoundly bound up with our capacity to sustain deep personal relationships like those between parents and children, 
lovers, and friends and it seems reasonable to suggest that concerns like these related to our own and others moral integrity will have deliberative priority over concerns with promoting the happiness of others and other less central moral interests. Notice also that given their structure, these arguments will pick out precisely those interests whose marginalization we tend to perceive as a great loss. Thus, it is because we naturally place such a high value on relationships like friendship that they merit special consideration. They will also serve to explain some important moral boundaries on claims of love and friendship and allow for critical discussion of claims to special status made on behalf of other relationships. So, for example, while it seems relatively straightforward to make a case for the centrality of family relationships and friendship, the partial treatment of fellow countryman normally associated with patriotism will be harder to justify on these grounds and a case will have to be made that national identity in some way bears importantly on issues of our psychological or moral integrity. Finally, this model will also lend itself to finer discrimination in particular cases. Thus, for example, it would naturally allow for special room to be given to relationships with family and friends in times of personal crisis when our psychological integrity is in jeopardy, but would nonetheless also require us to avoid any pathological dependence on friends and family likely to injure our moral integrity.

In contrast, efficiency arguments seem more limited. Given common disparities in levels of need, it will routinely be hard to justify preferring relatively affluent loved ones over impoverished strangers in obvious and immediate need on the grounds that I know those I care about better and am more confident that my efforts to help will pay off. These arguments will, however, still have some force in contexts in which needs are comparable and any perceived limitations in this case may well say more about our indifference to the plight of strangers than it does about possible shortcomings in these arguments. 


\section{IV}

I have argued that Herman's deliberative field model and her developmental account of desire formation are not directly responsive to the critic's demand for something more that toleration of motives of connection. Taken on its own, the deliberative field model does not change the basic dynamics of deliberation troubling to the critic; motives of connection and other interests and commitments will still be thought of as independent interests regulated by external moral requirements with deliberative priority, raising the same general concerns about the place afforded to these interests in our lives. Any changes in these dynamics therefore stem from the introduction of the developmental account of desire formation and, specifically, the organic elements of this account intended to collapse the distinction between self and moral interests. However, while we can think of interests as evolving in the reason-responsive manner Herman envisages, I have argued that doing so will still not meet the critic's demands. Whether these are interpreted in terms of a demand for affirmative moral endorsement of motives of connection, or in a more limited sense as a demand for structural accommodation, the critic will reasonably demand to be shown that reason-responsive development will preserve some meaningfully personal interests of the right sort.

I have claimed therefore that the Kantian committed to the priority of moral requirements who is concerned to answer the critic's challenge must avail herself of the kind of indirect argument that Herman begins by eschewing. Herman's account does, however, emphasize the complex structure of values in our lives and their different sources, and I have argued that when we combine this model with her limiting condition account of the motive of duty, these indirect arguments need not be regarded as necessarily flawed just in virtue of their form. While 
important questions of scope remain to be addressed, it seems to me that rather than forgoing these indirect arguments, the Kantian must and ought to endorse them. 
Bibliography

Baron, M. 1984. "The Alleged Moral Repugnance of Acting From Duty." The Journal of Philosophy, 81 (1984): 197-220.

Herman, B. 1996a. "Making Room for Character." In Aristotle, Kant, and the Stoics: Rethinking Happiness and Duty, ed. S. Engstrom and J. Whiting. Cambridge, UK: Cambridge University Press. Reprinted in Moral Literacy, Herman 2007.

--- 1996b. The Practice of Moral Judgment. Cambridge, MA: Harvard University Press.

--- 2002. The Scope of Moral Requirement. Philosophy \& Public Affairs, 30 (2002): 227-

256. Reprinted in Moral Literacy, Herman 2007.

--- 2007. Moral Literacy. Cambridge, MA: Harvard University Press.

Kant, I. 1974. Anthropology from a Pragmatic Point of View, trans. M. J. Gregor. The Hague: Martinus Nijhoff.

--- 1991. The Metaphysics of Morals, trans. Mary J. Gregor. Cambridge, UK: Cambridge University Press.

Scheffler, S. 1994. The Rejection of Consequentialism. New York: Oxford University Press.

Railton, P. 1988. "Alienation, Consequentialism, and the Demands of Morality." In Consequentialism \& Its Critics, ed. S. Scheffler. New York: Oxford University Press.

Stocker, M. 1976. "The Schizophrenia of Modern Ethical Theories." The Journal of Philosophy, 73 (1976): 453-466.

Velleman, J. D. 1999. “Love as Moral Emotion.” Ethics, 109 (1999): 338-374.

Williams, B. 1981. Moral Luck. New York: Cambridge University Press.

Wilson, D. 2007. “Middle Theory, Inner Freedom, \& Moral Health,” History of Philosophy Quarterly, 24 (2007): 393-413.

Wolf, S. 1982. "Moral Saints” The Journal of Philosophy, 79 (1982): 419-439. 


\section{Endnotes}

${ }^{1}$ These different versions of the problem are obviously related, but can nonetheless be distinguished. We can conceive of a moral theory in which personal commitments are possible and can still serve as justifying reasons for action, but in which extensive practical commitments leave these interests troublingly impoverished or marginalized. In the limiting case of unrestricted practical moral commitment, however, agents may find themselves in the position of never being free to act from personal reasons and may effectively be in the same position as the agent in the formal variant. I emphasize this distinction here primarily because I will argue later that Herman's proposal cannot be understood as addressing the practical variant, and that the structural variant with which she seems to be concerned cannot be properly addressed without giving some explicit account of the moral relevance and relative value of personal interests.

2 I refer to Herman's model here as an "integrated value" model provisionally and with some reservations. The idea of an integrated value account serves to emphasize the way Herman's approach differs from the direct and indirect value models that she rejects. Contrasted with these models, her approach can be thought of integrating moral and personal values in a way that is renders the priority of morality compatible with the deeply partial commitments constitutive of personal relationships, without reducing the value of these relationships to a special kind of moral value or associating them with some distinct value. To the extent, however, that the idea of an integrated value account implies an original separation of values that are subsequently integrated, the term is, as we shall see later, somewhat misleading.

${ }^{3}$ I take it that by endorsing the demand for something more than mere toleration of motives of connection and by emphasizing the need to give these "essentially partial" commitments “noninstrumental expression" Herman means to defend a robust sense of partial commitment like this. In doing so, her response is positioned between two alternatives she seems to regard as unattractive: (i) a model that thinks of motives of connection as having indirect moral value in virtue of the kind of "mental health" argument she rejects; and (ii) an approach that reduces personal commitments like these to expressions of more general moral commitment (in which, for example, my love for my family is regarded as an appropriate local expression of the 
general moral regard owed to humanity as such). I think that Herman is right to insist on preserving a sense of the distinct partiality of these interests and hence in rejecting the second of these alternatives and do not therefore discuss it directly here.

${ }^{4}$ Slightly modifying Herman's model, Marcia Baron offers a similar response. She suggests that "the sense of duty can function in two very different ways": (i) as a regulating secondary motive, in which case the agent has another explicit primary motive; or (ii) as an explicit primary motive as in cases of moral difficulty where effort is needed to move one to act as morality requires. Thinking of the motive of duty as typically serving as a secondary motive, she then denies that acting from the motive of duty always demands the explicit and alienating recognition and endorsement of the moral character of one's actions in the moment of acting (Baron, 208).

${ }^{5}$ Considering a similar distinct value approach in relation to consequentialist ethics, Samuel Scheffler emphasizes that this kind of divided self model only worsens the problem by dividing the self into two personalities: some of the time we are to function as perfect egoists pursuing our own partial interests and the rest of the time we are to adopt the impartial moral perspective of consequentialism and live our lives on this basis. Rather than reconciling our moral and personal commitments Scheffler therefore claims that this response would just cement their separation and thereby "undermine the unity and consistency of personality that are prerequisites for living a life of integrity" (Scheffler, 1994, 18).

${ }^{6}$ Notice also that the special nature of motives of connection makes questions about the scope of these interests crucial. As Herman puts it:

..the relationships between parents and children, between friends, lovers, neighbors, are essentially partial. It is because someone is my neighbor, lover, or child, that I have reasons for action of a certain sort. Having these relationships is to have these reasons. They are reasons of considerable strength and priority and they are reasons such that acting on them (and not on other reasons that can produce the same outcomes) is important to maintaining the relationships that generate them. The importance of these reasons derives from connections of feeling, familiarity, love (Herman, 1996a).

This kind of partiality and immediacy of connection is not merely a matter of the structure or form of these interests. It is not enough to argue that organically evolved interests in one's own 
children will come naturally to reflect principled norms of fairness, etc. and that there is no structural opposition between morality and personal interests of this sort. We need to be confident that the moral requirements these interests internalize will leave room for the kind of meaningfully partial regard partly constitutive of (and essential to) these relationships and thus make them meaningfully possible for us.

7 As I will emphasize below, this kind of engagement and deliberation need not be understood as requiring the sort of intrusive and constant self-scrutiny and evaluation sometimes associated with the Kantian demand that we always act from the motive of duty. I mean only that the Kantian moral agent acts deliberately with some understanding of the moral character of their choices and conduct and that, as David Velleman puts it, Kantian moral theory thus "makes fundamental demands on an agent's practical thought," requiring agents to be "morally minded and not just morally behaved" (Velleman, 339-340).

${ }^{8}$ For a more comprehensive discussion of the role of these kinds of psychological considerations in Kant's treatment of duties see Wilson, 2007. I argue here that various duties of virtue Kant discusses in the Metaphysics of Morals can be regarded as systematically oriented around concerns with ensuring our capacity for moral agency and that this suggests an attractive and subtle account encompassing a range of psychological concerns.

9 Making a similar point in a footnote, Herman remarks that:

We should at least mark that there is a question about why something that is slotted as of instrumental value does not bear the value of its end. This may have something to do with a tendency to believe that instruments are fungible. It does not seem to be a necessary truth about value (Herman 1996a, 187, ftnt. 5).

In fact, in her later work Herman frequently describes the moral value of relationships and, more generally, our own happiness in indirect terms and argues that indirect moral value can be compatible with direct value attributed on other grounds. Reflecting Kant's remarks on the indirect importance of our own happiness she notes that "If we do not care enough about ourselves, we may become less able agents: we can lose the courage to act well or the strength to resist temptation" (Herman, 2002, 242) and suggests that: 
The instrumental role of enjoyment does not make enjoyment instrumental. It rather explains why morality takes it seriously (Herman, 2002, 242)

It is not, however, clear to me whether she means to endorse an explicit role for indirect arguments in individual practical deliberation here or, instead, to develop further the radical transformation of Kantian ethics outlined in "Leaving Deontology Behind" (Herman, 1996b, Chp. 10) in a way that continues to forgo the use of these arguments in personal moral reflection. The point I want to stress is simply that the Kantian cannot forgo these arguments and ought not to be shy of endorsing them.

${ }^{10}$ For an interesting discussion of this and related issues see Peter Railton's “Alienation, Consequentialism, and the Demands of Morality" (1988). Railton argues that important utilities associated with relationships like friendship cannot be realized by adopting an instrumental attitude towards them, and that the sophisticated consequentialist will therefore have utilitarian reasons for valuing these relationships directly on their own terms.

${ }^{11}$ In light of the fact that indirect arguments like this begin with the reality of deep personal affections and are focused precisely on making room for the "lived character" of these relationships in a moral life, it is hard to see why they should be regarded as so troubling by critics - at least once we argue that the agent is not required always to act explicitly in the moment from a sense of the impartial moral value of these relationships. Perhaps the concern here is not that the agent is alienated from particular relationships but, instead, that there is something troubling or impoverishing about thinking of the value of important goods like friendship and parental love in these indirect terms (and thus that the problem of alienation arises here, or recurs, at the level of reflection on the way in which the value of these types of relationships is understood).

If so, however, then the burden seems to me to be on the critic to explicitly make the case that there is something inappropriate or demeaning about this model. The indirect moral value account is perfectly compatible with our thinking that relationships like friendship also have other kinds of value not reducible to their instrumental value in promoting our well-being and hence, indirectly, our moral integrity. It is also compatible with distinctions in types of friendships and with our thinking of some types as more valuable than others on either moral 
or non-moral grounds. Thus, for example, there is nothing that precludes us from distinguishing between casual and deeper friendships and viewing the latter as being more significant either in terms of some ideals of friendship or in those of their moral significance. Likewise, we can distinguish friendships of convenience and those based on a genuine appreciation of the character of one's friends on either of these grounds. In fact, the only model that seems precluded is one that assigns non-moral intrinsic or instrumental value to these relationships and regards this value as taking precedence over moral requirements. In this case, however, it is the priority afforded to moral considerations in Kantian ethics that is the source of the problem and not the indirect valuing of these relationships. And, thus understood, the criticism is one that elevates the pursuit of personal affections and interests over the requirements of moral life in a way that has deeply counterintuitive implications in its own right.

${ }^{12}$ Scheffler understands the problem in the same way tracing it to consequentialism's "strict proportionality requirement" (the requirement that the agent "allocate energy and attention to the projects and people he cares most about in strict proportion to the value from an impersonal standpoint of his doing so" (Scheffler, 1994, 9)).

In associating the problem with the basic structure of consequentialist reasoning, both authors forgo a standard simpler utilitarian response that gives special priority to important personal commitments on the grounds of their significance for agents and their connection with personal integrity. The suggestion here is that given the special utilities associated with these relationships room will be left for them in moral life and that sacrifices that are demanded of us will now reflect the special value of our own and others' important relationships. As Railton and Scheffler see it, simply acknowledging the impartial moral value of non-alienation does not change the situation of the agent who is still required to view these commitments impartially on the basis of their general utility and therefore still cannot give any special weight to her own relationships simply as her own. Reflecting the same demand for something more than toleration of motives of connection that Herman endorses, Railton therefore rejects this simpler solution emphasizing that "the problem seems to be in the way in which morality 
asks us to look at things, not just the things it asks us to look at" and that these solutions offer us "too little, too late" (Railton, 1988, 100).

${ }^{13}$ Scheffler emphasizes that it is not irrational for a moral theory to be self-effacing in this way and that it is ad hoc to simply appeal to something like a publicity condition as a requirement in any acceptable moral theory (Scheffler, 1994, 46-53). If, however, the aim here is to reconcile the moral and the personal in the individual's life, it seems deeply unsatisfactory to do so by rendering the individual's personal sense of moral commitment entirely fungible and arguing that they should come to adopt whatever view brings them to lead the most objectively consequentialist life available to them. 